\title{
ANNOTATION
}

\section{TRICHOMONAS VAGINALIS}

Although infestation with Trichomonas vaginalis is a very common condition in women and is also one possible cause of non-specific urethritis in the male, little advance in our knowledge of trichomonas vaginitis has been made in recent years. The reason for this may be that most workers have concentrated on trials of new drugs for local vaginal treatment in the female. Aureomycin both by mouth and vaginally has recently been used with varying results (McVay and others, 1949 ; Nicol, Gallagher, and King, 1952). Investigations will continue in the hope of finding a drug which will act systemically ; drugs acting on other protozoa by this route are always worthy of trial. It is probable that vaginal treatment alone will not eradicate this infection, since trichomonads may also be present in the glands of Bartholin and Skene, and in the urethra, urethral glands, and bladder, and may also pass through the cervix and uterine cavity into the Fallopian tubes and cause pelvic inflammation. Little attention has been paid to this last possibility in recent years, but with the cooperation of the gynaecologists it should be possible to confirm or refute the work of Rodecurt (1936) and Jírovec and others (1942).

Another point of great importance which is still very controversial is the true incidence of trichomonas infection in males with non-specific urethritis. Since Liston and Lees (1940) gave their paper on the subject, the results obtained by workers in Great Britain have varied greatly. Although the finding of the organism by a wetslide method is most reliable, it appears that the movements of the trichomonads are often very sluggish when seen in subpreputial or urethral discharge or in prostatic secretions and centrifuged urine. This may be due to $p \mathrm{H}$ variation and can make diagnosis by this method very difficult. Further research is needed to correlate wet-film findings with cultural results using a suitable medium such as that of Adler and Pulvertaft (1944) of or Lash (1950). Whittington (1951a, b), working in a sterility clinic, examined semen by the use of cultures as well as by the moist-slide method. The husbands of 26 women with trichomonas vaginitis were thus examined, and seven ( 27 per cent.) were found to be positive ; only one of these men had subjective symptoms. In a control group of ten husbands of women free from $T$. vaginalis, no flagellates were demonstrated. In addition to these methods, stained slides may be examined by one of the methods listed by Trussell (1947); this is successful only if slides are carefully fixed so that the flagellar structure can be identified.

$T$. vaginalis multiplies by division and there is no convincing proof of cyst formation. Those who have reported cysts may have in fact seen the yeast forms of monilia. Also with a fall in temperature and with a change in $p \mathrm{H}$, motile forms may furl their flagella peripherally and be mistaken for cysts. Sometimes motile forms with two or four sets of flagella may be seen in cultures and may represent failure of the cytoplasm to divide under unfavourable conditions. However the possibility of the fusion of several trichomonads cannot be excluded. It is curious that evidence of division is rarely seen in wet specimens taken from the vagina or in vaginal slides stained to demonstrate nuclear division. This might suggest that multiplication of the trichomonads occurred elsewhere than in the vagina.

It is well known that over 50 per cent. of females with acute gonorrhoea also harbour Trichomonas vaginalis. The significance of the close correlation of trichomonas and pleuropneumonia-like organisms in the vagina as shown by Salaman (1946) has still to be explained. It might suggest similar correlation in males with non-specific urethritis, but there is no proof of this at present.

Lastly, the very nature of this condition is in doubt. Trussell (1947), having reviewed the evidence, feels that trichomonas infection is usually sexually transmitted; Trussell and Plass (1940) reported inoculation of the female vagina with bacteria-free cultures of $T$. vaginalis producing typical vaginitis in a number of cases. If we accept 
transmission of the disease by sexual intercourse, this does not exclude the possibility of the transference by other means which can certainly occur in syphilis and gonorrhoea. Kessel and Thompson (1950) demonstrated the survival to $T$. vaginalis in vaginal discharge, and Whittington $(1951 \mathrm{a}, \mathrm{b})$ has shown that the organism may survive in tap water. These papers suggest the possibility of spread of infection by fomites and even by bathing in freshwater swimming pools.

In approaching the various problems concerning $T$. vaginalis, it should not be forgotten that Trichomonas foetus infection of cattle is known to be a venereal disease - that the bull, which usually has a balanitis, may also have a urino-genital infection which cannot be cured. This organism definitely invades the uterus to produce abortion in the cow, but is a self-limiting disease. It is possible that we may gain more understanding of trichomonas vaginitis by studying the literature from veterinary sources on the Trichomonas foetus. In this respect the papers by Kerr and Robertson (1946a, b ; 1947) and by Kerr, McGirr, and Robertson (1949) on vaccination, localization of antibody in the genital tract, and antibody formation in the blood in relation to agglutination and intradermal tests in cattle, are of interest.

\section{REFERENCES}

Adler, S., and Pulvertaft, R. J. V. (1944). Ann. trop. Med. Parasit., $38,188$.

Jirovec, O., Breindl, V., Kučera, K., and Šebek, V. (1942). Z Zbl. Bakt., I. Abt. Orig., 148, 338.

Kerr, W. R., McGirr, J. L., and Robertson, M. (1949). J. comp. Path., 59, 133.

, and Robertson, M. (1946a). Ibid., 56, 38.

- — (1946b). Ibid., 56, 101.

-_ (1947). Ibid., 57, 301.

Kessel, J. F., and Thompson, C. F. (1950). Proc. Soc. exp. Biol., N.Y., 74, 755.

Lash, J. J. (1950). Amer. J. trop. Med., 30, 641.

Liston, W. G., and Lees, R. (1940). British Journal of Vencreal Diseases, 16, 34.

McVay, L. V., Laird, R. L., Flanagan, J. B., and Sprunt, D. H. (1949). Proc. Soc. exp. Biol., N.Y., 72, 674.

Nicol, C. S., Gallagher, E., and King, A. J. (1952). British Journal of Venereal Diseases, 28, 142

Rodecurt, M. (1936). Zbl. Gynäk., 60, 3028.

Salaman, M. H. (1946). British Journal of Venereal Diseases, 22, 47.

Trussell, R.E.(1947). “ Trichomonas Vaginalis and Trichomoniasis." Blackwell, Oxford.

-

Whittington, M. J. (1951a). J. Obstet. Gynaec. Brit. Emp., 58, 615. -(1951b). J. Hyg., Lond., 49, 400.

\section{ANNOUNCEMENT}

The third annual conference of the Marseilles branch of the Société Française de Dermatologie et de Syphiligraphie will be held in Marseilles on October 17, 18, 19, and 20, 1952. Papers on "The treponemal immobilization test, its technique, results, significance, and practical value" will be presented.

Particulars can be obtained from Dr. J. Bonnet, the General Secretary of the Society, Clinique Dermatologique, Hôtel-Dieu, Marseilles. 